\title{
Single dose gamma irradiation induced angiogenesis in rat skin hair follicles
}

\author{
Gh.K. El Khalafawy', A.A. Elkady ${ }^{1}$, S.S. Sayed ${ }^{2}$, A.F. El Bedewi ${ }^{*}$ \\ ${ }^{1}$ Health Radiation Research Department, National Center for Radiation Research and Technology (NCRRT), \\ Egyptian Atomic Energy Authority, Cairo, Egypt \\ ${ }^{2}$ Histology Department- Faculty of Medicine- Cairo University, Cairo, Egypt
}

\section{- Original article}

\section{*Corresponding authors:} Ahmed Fathy El Bedewi, M.D., E-mail: aelbedewi@gmail.com

Revised: November 2019

Accepted: January 2020

Int. J. Radiat. Res., October 2020; 18(4): 693-698

DOI: 10.18869 /acadpub.ijrr.18.4.693

\section{ABSTRACT}

Background: Hair follicle cycling usually associated with prominent changes in skin vascularization; through follicular dermal papilla production of angiogenic factors. The early response of hair follicles to ionizing irradiation (IR) is induction of early anagen hair and appearance of new hair formation. Material and Method: Fifty rats were equally divided into 2 groups; control and $\gamma$-rays (10Gy) as a single dose, skin biopsy was taken from dorsum of the rat 72 hours after irradiation. Skin biopsy was examined histopathological and with immunohistochemical staining CD31. Blood samples were collected for biochemical analysis of Tumor necrosis factor- $\alpha$ (TNF- $\alpha$ ), Interleukin-1 $\beta$ (IL1ß), Interleukin-6 (IL-6), Malondialdehyde (MDA), Catalase (CAT) and Superoxide dismutase (SOD) Results: $\gamma$-rays produced epidermal thinning and dermal inflammatory cells together with dermal endothelial proliferation and new vessels formation around the hair follicle compared with control group as demonstrated by CD31 staining. Furthermore, there was a significant elevation of TNF- $\alpha, I L-1 \beta$ and IL- 6 levels compared to control group. Moreover, MDA levels increased significantly in $\gamma$-rays group and decreased significantly in control group, whereas CAT and SOD activities decreased in the $\gamma$-rays compared with the control group. Conclusion: The early effects of $\gamma$ -rays on the skin could be beneficial and stimulatory to hair growth.

Keywords: y-rays, hair follicles, angiogenesis, CD31, rats.

\section{INTRODUCTION}

Angiogenesis is the growth of new capillaries from pre-existing blood vessels (1). Skin angiogenesis is a common feature during fetal development; whereas secondary angiogenesis in adult skin usually arises in wound healing, psoriasis and in association with tumors. Hair follicles represent a unique feature of cyclical transformations from growth phase (anagen) followed by regression phase (catagen), and then relative phase "quiescence" (telogen). Skin vasculature and perfusion rearrangement are frequently correlated with hair follicle cycling; dermal tissues surrounding anagen hair follicles are more vascular than telogen due to the proliferating endothelial cells (PEC) inside the follicular dermal papilla. Furthermore, catagen shows some degeneration of the capillary loops within the dermal papilla.

The epithelial hair bulb of anagen follicles, outer root sheath keratinocytes and dermal papilla fibroblasts are usually the sources of angiogenic factors: vascular endothelial growth factor (VEGF), hypoxia inducible factor (HIF-1 $\alpha$ ) and matrix metalloproteinase (MMP-2) (2).

Radiation can affect vessel growth through photon stimulation of vessel growth and increases expression of angiogenic factors; $\gamma$-rays promote angiogenesis and increase metastasis (often by causing an increase in the expression of pro-angiogenic factors such as VEGF, HIF-1 $\alpha$, IL-6, and basic fibroblast growth 
factor (b-FGF) in the irradiated tissue) (3-5).

Ionizing radiation is also known to cause oxidative stress through a generation of reactive oxygen species (ROS) resulting in an inequity of the pro-oxidant and antioxidant in the cells (6). High level of nitric oxide (NO) appears to enhance oxidative stress through its oxidative and apoptotic influence. In addition to these influences, there are also some studies that show that NO participates in angiogenesis. It was reported that angiogenesis induced by VEGF can be slowed in vivo by NO-synthetase inhibition. It seems that NO participates in the angiogenic activity of VEGF (7).

The current study aims to evaluate the histopathological and microcirculatory skin alteration induced by $\gamma$-rays in rats.

\section{MATERIALS AND METHODS}

\section{Animals}

Fifty adult male Swiss albino rats (120-130g) were obtained from the Egyptian organization for biological product and vaccines Giza, Egypt. Animals received the standard requirements of food and water ad libitum and maintained under environmental conditions of humidity, temperature $\left(20-22^{\circ} \mathrm{C}\right)$, and 12 -h light-dark cycle. All procedures performed in this study were in accordance with the ethical standards of the REC-NCRRT, Egyptian Atomic Energy Authority, Egypt following the guidelines of NIH at which the studies were conducted (National Research Ethics Committees REC-NCRRT, Egypt + permit number: 11A /18).

\section{Irradiation}

It was done using Gamma-cell-40 (Cesium137) located at NCRRT, Nasr City, Cairo, Egypt. Animals were exposed to a single dose of $10 \mathrm{~Gy} \gamma$ -rays delivered at a rate of $0.42 \mathrm{~Gy} / \mathrm{min}$ at the time of experimentation.

\section{Experimental design and sample collection}

All rats were divided into 2 groups $(n=25)$; control and $\gamma$-rays group (animals were irradiated with an acute single dose of $10 \mathrm{~Gy}$ ). After the $3^{\text {rd }}$ day post irradiation, and an overnight fast, blood samples were collected by retro-orbital puncture from each rat using blood capillary tubes. Blood samples were collected in dry sterile tubes then, serum was separated using a refrigerated centrifuge at 3000 r.p.m. for $15 \mathrm{~min}$, stored frozen at $-20^{\circ} \mathrm{C}$ till biochemical analysis. Skin biopsies were taken from the dorsum of each rat and fixed in $10 \%$ buffered formalin solution followed by dehydration, cleated and embedded in paraffin. Paraffin sections of 4-micron thickness were prepared and stained with both of Haematoxylin and Eosin (H\&E) according to Suvarna et al. (8) and stained immunohistochemically for CD31 (9). At the end of the experiment, rats were sacrificed on the $3^{\text {rd }}$ day post radiation exposure.

\section{Immunohistochemical staining}

CD31 also known as Platelet endothelial cell adhesion molecule-1 (PECAM-1/CD31); is obtained from (Thermo Fisher, MA-USA) with dilution $1: 100$. It is $130-\mathrm{kDa}$ membrane glycoprotein that belongs to the immunoglobulin supergene family and is constitutively expressed on the surface of endothelial cells, platelets, and circulating leukocytes and is commonly used as an endothelium-specific marker (10). Mounting evidence implicates its involvement in a number of cell adhesion processes that take place in the vasculature, such as leukocyte adhesion and transmigration, the adherence of platelets to the vascular wall at sites of endothelial cell damage, endothelial cell-cell adherence and migration, a process required for neovascularization that is essential for tissue growth and repair.

\section{Estimation of biochemical parameters}

Serum tumor necrosis factor alpha (TNF- $\alpha$ ), Interleukin-1 $\beta$ (IL-1 $\beta$ ) and Interleukin-6 (IL-6) activities were done by Enzyme-Linked Immunosorbent Assays (ELISA) technique (BioSource International, Camarillo, CA, USA) according to the manufacturer's instructions. All samples assay was repeated three times. 
(Thermo Scientific Multiskan MK3, USA). Also, MDA level was evaluated following the method described by Buege and Aust (11). CAT activity was assayed using the method of Sinha (12) and SOD was determined according to the method designated by Kakkar et al. (13).

\section{Statistical analysis}

Data were investigated using SPSS software (version 19.0). One way analysis of variance (ANOVA) followed by LSD as Post Hoc test were used. The results obtained were calculated by mean \pm standard deviation. P-values $<0.05$ were considered to be statistically significant (14).

\section{RESULTS}

Histopathological sections of irradiated rat skin revealed thinning of the epidermis layer with flattened rete ridges with large nuclei together with vacuolation and spongiosis. Absence of stratum corneum and vesicles formation were rarely seen. Collagen fibers were disorganized and appeared more eosinophilic and homogenous. Dermal elastic fibers were fragmented and clumped (figure 1).

There was positive CD31 immunoreactivity involving the blood vessel endothelium in the control and $\gamma$-irradiated rats (figure 2). Furthermore, single dose (10 Gy) of $\gamma$-rays resulted in strong positive CD31 immunoreactivity around hair follicles which was abundant in the control (figures 3 and 4).

A significant rise in the level of inflammatory cytokines TNF- $\alpha$, IL-1 $\beta$ and IL- 6 was detected in $\gamma$ - irradiated group compared to the control group (table 1). Moreover, $\gamma$ irradiation induced significant down-regulation in the activity of CAT and SOD and significant up-regulation in the level of MDA compared to the control group (table 2).
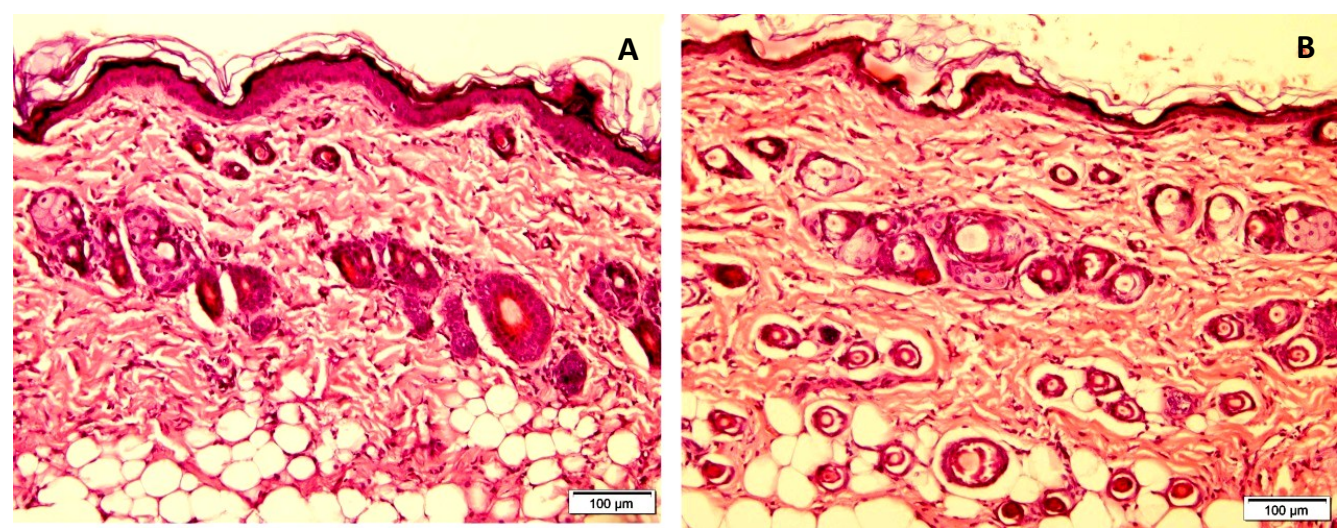

Figure 1. Rat skin sections showing: in (A) control group showing normal appearance of the epidermis and the hair follicles and in (B) irradiated group showing thinning of the epidermis (H\&E x 100).

Figure 2. Skin of control rat showing strong positive CD31 immunoreactivity involving the blood vessel endothelium (arrows), while it was absent around th hair follicles (CD31 Immunohistochemical staining x 400).

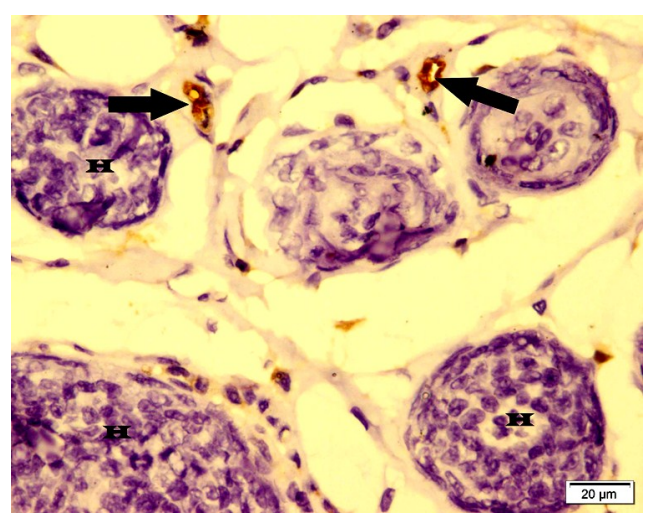




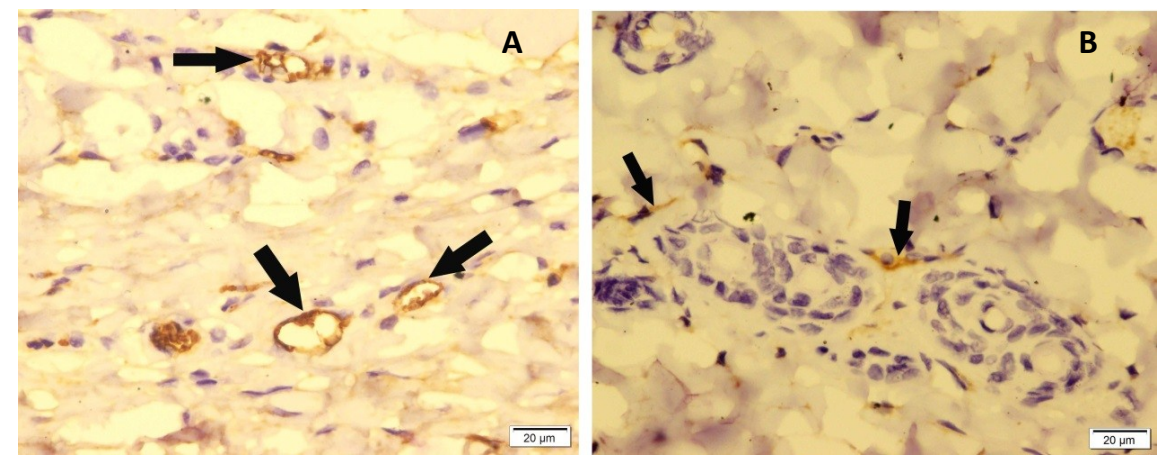

Figure 3. skin section of rat showing: (A) control group abundant positive CD31 immunoreactivity (arrows) around blood vessels and in (B) irradiated group strong positive CD31 immunoreactivity in individual cells (arrows) close to the hair follicles (CD31 Immunohistochemical staining $\times$ 400).
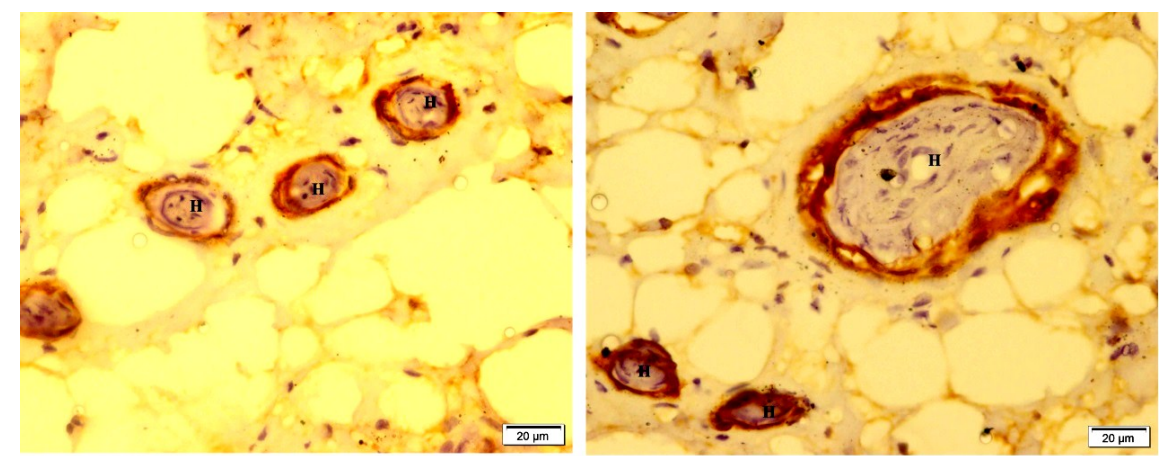

Figure 4. Skin section of rat exposed to $10 \mathrm{~Gy}$-rays showing strong positive CD31 immunoreactivity around the hair follicles (H). (CD31 Immunohistochemical staining x 400).

Table 1. Inflammatory cytokines levels before and after $\gamma$ irradiation.

\begin{tabular}{|c|c|c|}
\hline Inflammatory Cytokines & Control & Irradiated \\
\hline TNF- $\boldsymbol{\alpha}(\mathbf{p g} / \mathbf{m l})$ & $30.34 \pm 1.02$ & $81.53 \pm 2.39^{\mathrm{a}}$ \\
\hline IL-1 $\boldsymbol{\beta} \quad(\mathbf{p g} / \mathbf{m l})$ & $10.63 \pm 0.74$ & $53.89 \pm 1.91^{\mathrm{a}}$ \\
\hline IL-6 $\mathbf{( p g / m l )}$ & $80.12 \pm 1.27$ & $175.31 \pm 4.76^{\mathrm{a}}$ \\
\hline
\end{tabular}

\section{DISCUSSION}

Hair follicles have long been recognized as a potential marker for radiation injury. Moreover, hair follicle cycling is associated with significant changes in skin perfusion, the epithelial hair bulbs of anagen follicles and the follicular dermal papilla express angiogenic factors (15).

Angiogenic growth factors such as VEGFs and b-FGFs induce the secretion of endothelial proteinases and plasminogen activators that cause the breakdown of the vessel basement membrane, allowing the cells to interrupt the adjoining matrix. Subsequently, the endothelial cells migrate, multiply and ultimately
Table 2. Anioxidant levels before and after $y$ irradiation.

\begin{tabular}{|c|c|c|}
\hline Biochemical parameter & Control & $\gamma$-Irradiated \\
\hline CAT (U/mg protein) & $2.06 \pm 0.72$ & $1.42 \pm 0.91^{\mathrm{a}}$ \\
\hline SOD (U/mg protein) & $3.66 \pm 0.97$ & $1.07 \pm 0.94^{\mathrm{a}}$ \\
\hline MDA (nmol/g protein) & $8.23 \pm 1.98$ & $16.07 \pm 2.54^{\mathrm{a}}$ \\
\hline
\end{tabular}

differentiate to give rise to a new, lumen-comprising vessel. Thereafter, the endothelial cells establish a new basement membrane and release additional factors such as platelet-derived growth factor (PDGF), which draws the supporting pericytes to interact externally with the endothelial cells in order to stabilize the newly formed vessels (16).

Hair follicle stem cells (HFSCs) have a powerful expansion capability and multidifferentiation potential properties. Recently, Xu et al. (17) revealed an efficient strategy of hair follicle HFSCs differentiation into endothelial cells by stimulation with VEGF and PFGF. Moreover, HFSCs expressed endothelial cell (EC)

Int. J. Radiat. Res., Vol. 18 No. 4, October 2020 
-related markers, including von Willebrand factor (vWF), vascular endothelial cadherin (VE) -cadherin and CD31. Furthermore, VEGF165 induced differentiation from HFSCs into vascular endothelial cells (18).

In the current study a single dose of a whole body gamma irradiation (10 Gy) induced a significant up-regulation in the level of TNF- $\alpha$, IL-1 $\beta$ and IL-6 as shown in (table 1). Several in-vivo and in-vitro studies revealed that TNF- $\alpha$ and IL-1 $\beta$ are the most important pro-inflammatory cytokines that exhibit a principle role in acute and chronic inflammation and in a variety of human diseases including autoimmune disorders, atherosclerosis, and cancer (19). Up-regulation of TNF- $\alpha$ and IL-1 $\beta$ expression was also found in lung and intestine after irradiation $(20,21)$. IL- 6 is another multifunctional pro-inflammatory cytokine that plays a main task in the mediation of the inflammatory and immune reactions originated by infection or injury (22). In 2012 Getz and her colleagues (23) demonstrated that IL-6 promotes STAT3 phosphorylation and early activation of angiogenesis-related gene transcription, which leads to increased angiogenesis. Recently, in 2019 Jin and his colleagues (24) revealed that hypoxia induces expression of TNF- $\alpha$ by endothelial cells (ECs), which represents an autocrine loop that activates the HIF pathway via an NF- $\kappa B$-dependent process, which facilitate VEGF production by ECs and angiogenesis.

Our study revealed for the first time that single acute dose of 10 Gy $\gamma$-rays induced after 72 hours, a significant angiogenesis around hair follicles was demonstrated by strong CD31 immunoreactivity which could be due to the up-regulation of IL- 6 and TNF- $\alpha$ leading to release of VEGF from hair follicles. So, it seems that $\gamma$-rays induced indirectly angiogenesis through expression of angiogenesis-related genes and pro-angiogenic factors. In 2014 Kinoshita and his (25) colleagues reported that radiation induced anagen, and new hairs were clearly visible after 1 week of single dose $\gamma$-rays (10 Gy).

On the other hand, exposure to $\gamma$-irradiation raises the production of ROS and directs the irradiated cells into a state of oxidative stress that has been concerned in a variety of natural and pathological processes (26). Recently in 2018 Soni and his colleagues (27) added that skin antioxidants were sensitive to radiation even at a low dose, which can be used as an indicator of radiation injury and changed in a dose-dependent manner. The current study showed a significant decrease in CAT and SOD together with significant rise in the level of MDA related to control group (table 2). In 2011 Pande and his coworkers (28) revealed that VEGF and MDA levels increased simultaneously and were positively correlated, VEGF is up-regulated by conditions associated with the generation of free radicals and reactive oxygen intermediates.

\section{CONCLUSION}

Radiation induced angiogenesis which usually associated with anagen which offers an attractive model for identifying the physiologic control of cutaneous angiogenesis, and a potential use of anti-angiogenic drugs in-vivo.

\section{Conflicts of interest: Declared none.}

\section{REFERENCES}

1. Chung J and Eun $H(2007)$ Angiogenesis in skin aging and photoaging. J Dermatol, 34(9): 593-600.

2. Yano K, Brown L, Detmar M (2001) Control of hair growth and follicle size by VEGF-mediated angiogenesis. J Clin Invest, 107(4): 409-417.

3. Prise K, Pinto M, Newman H, Michael B (2001) A review of studies of ionizing radiation-induced double-strand breaks clustering. Radiation Res, 5: 572-576.

4. Grabham $P$ and Sharma $P$ (2013) The effects of radiation on angiogenesis. Vasc Cell, 5: 19.

5. Srinivasan M, SudheerA, Pillai R (2007) Modulatory effects of curcumin on $\gamma$-radiation-induced cellular damage in primary culture of isolated rat hepatocytes. Environmental Toxicol Pharmacol, 24: 98-105.

6. Papapetropoulos A, Garcia-Cardena G, Madri J, Sessa W (1997) Nitric oxide production contributes to the angiogenic properties of VEGF in human endothelial cells. J Clin 
Invest, 100: 3131-3139.

7. Suvarna S K, Layton C, Bancroft D J (2012) Bancroft's theory and practice of histological techniques E-Textbook - 7th Edition- ISBN.

8. Ananiev J, Penkova M, Slaveykov K, Tchernev G (2014) Immunohistochemical Expression of Endothelial Cell Markers in Case of Dieulafoy Lesion: Is There Is a Differences. Science Journal of Clinical Medicine, 3(4): 70-74.

9. Ilan N, Cheung, L, Pinter E, Madri J (2000) Plateletendothelial cell adhesion molecule-1 (CD31), a scaffolding molecule for selected catenin family members whose binding is mediated by different tyrosine and serine/ threonine phosphorylation. J of biological Chemistry, 275 (28): 21435-21443.

10. Buege J and Aust S (1978) Microsomal lipid peroxidation. Methods in Enzymology, 52: 302-310.

11. Sinha K (1972) Colorimetric assay of catalase. Anal Biochem, 47: 389.

12. Kakkar, P, Das B, Viswanathan, PN (1984) A modified spectrophotometric assay of superoxide dismutase. Ind J Biochem Biophys, 21: 130-132.

13. Snecdecor GW and Cochran WG (1989) Statistical Methods, 8th Edition, Wiley-Blackwell, P: 503.

14. Mecklenburg L, Tobin D, Müller $S$, et al. (2000) Active hair growth (Anagen) is associated with angiogenesis. J Invest Dermatol, 114: 909-916.

15. Chung AS, Lee J, Ferrara N (2010) Targeting the tumor vasculature: Insights from physiological angiogenesis. Nat Rev Cancer, 10: 505-514.

16. Xu Z, Zhang Q, Li H (2014) Differentiation of human hair follicle stem cells into endothelial cells induced by vascular endothelial and basic fibroblast growth factors. Mol Med Rep, 9(1): $204-10$.

17. Quan R, Du W, Zheng X, Xu S, Li Q, Wu X, Shao R, Yang D (2017) VEGF165 induces differentiation of hair follicle stem cells into endothelial cells and plays a role in in vivo angiogenesis. J Cell Mol Med, 21(8): 1593-1604.

18. Locksley R, Killeen N, Lenardo M (2001) The TNF and TNF receptor superfamilies. Integrating mammalian biology Cell, 104: 487-501.

19. Hong JH, Chiang, CS, Tsao, CY, Lin PY, McBride WH, Wu CJ (1999) Rapid induction of cytokine gene expression in the lung after single and fractionated doses of radiation. International Journal of Radiation Biology, 75(11): 1421-1427.

20. Linard C, Marquette C, Mathieu J, Pennequin A, Clarencon $D$, Mathe D (2004) Acute induction of inflammatory cytokine expression after $\gamma$-irradiation in the rat: Effect of an NF-kappaB inhibitor. Int J Rad Onco Biol Phys, 58(2): 42734.

21. Kishimoto $T$ (2005) Interleukin-6: From basic science to medicine -40 years in immunology. Annual Review of Immunology, 23: 1-21.

22. Gertz K, Kronenberg G, Kälin RE, Baldinger T, Werner C, Balkaya M, Eom GD, Hellmann-Regen J, Krober J, Miller KR, Lindauer U, Laufs U, Dirnagl U, Heppner FL, Endres M (2012) Essential role of interleukin-6 in poststroke angiogenesis Brain, 135(6): 1964-1980.

23. Jin F, Zheng $X$, Yang $Y$, Ye L, Doeppner TR, Hermann DM, Wang H, Dai $Y$ (2019) Impairment of hypoxiainduced angiogenesis by LDL involves a HIF-centered signaling network linking inflammatory TNF- $\alpha$ and angiogenic VEGF. Aging (Albany NY) 81; 11(2): 328-349. doi: 10.18632/aging.101726.

24. Kinoshita K, Ishimine H, Shiraishi K, Kato H, Doi K. Kuno S, Kanayama K, Mineda K, Mashiko T, Feng J, Nakagawa K, Kurisaki A, Itami S, Yoshimura K (2014) Cell and Tissue Damage after Skin Exposure to lonizing Radiation: Shortand Long-Term Effects after a Single and fractional doses. Cells Tissues Organs, 200(3-4): 240-252.

25. Sonveaux P, Brouet A, Havaux X, Gregoire V, Dessy C, Balligand JL, Feron $O$ (2003) Irradiation-induced angiogenesis through the up-regulation of the nitric oxide pathway: implications for tumor radiotherapy. Cancer Res, 63(5): 1012-1019.

26. Soni S, Basu M, Agrawal P, Bhatnagar A (2019) Evaluation of gamma radiation-induced biochemical changes in skin for dose assessment: A Study on Small Experimental Animals. Disaster Med Public Health Preparedness, 13(2): 197 $-202$.

27. Pande D, Negi R, Khanna S (2011) Vascular Endothelial Growth Factor Levels in Relation to Oxidative Damage and Antioxidant Status in Patients with Breast Cancer. J Breast Cancer, 14(3): 181-184. 